American Journal of Applied Sciences 4 (3): 133-141, 2007

ISSN 1546-9239

(C) 2007 Science Publications

\title{
The Characterization of Al Bond Pad Surface Treatment in Electroless Nickel Immersion Gold (ENIG) Deposition
}

\author{
${ }^{1}$ M.K. Md Arshad, ${ }^{2}$ A. Jalar, ${ }^{3}$ I. Ahmad and ${ }^{4}$ G. Omar \\ ${ }^{1}$ School of Microelectronic Engineering, Kolej Universiti Kejuruteraan Utara Malaysia (Kukum), Blok A, \\ Kompleks Pusat Pengajian Kukum, Jalan Kangar-Arau, 02600 Jejawi, Perlis, Malaysia \\ ${ }^{2}$ Department of Applied Physics, University Kebangsaan Malaysia, 43600 Bangi, Selangor, Malaysia \\ ${ }^{3}$ Department of Electrical, Electronics and System, University Kebangsaan Malaysia \\ 43600 Bangi, Selangor, Malaysia \\ ${ }^{4}$ On Semiconductor, SCG Industries (M) Sdn. Bhd. Lot 122, 70450 Senawang \\ Negeri Sembilan, Malaysia
}

\begin{abstract}
This study reports a number of experiments that were designed to characterize aluminum bond pad surfaces prior to electroless nickel immersion gold (ENIG). In the ENIG process, aluminum bond pads need special treatment to achieve successful nickel deposition and provide reliable interconnection of under bump metallurgy in advanced packaging. During this treatment process, the aluminum pad was cleaned, activated and then coated with a layer of zinc. Systematic study was carried out to determine the best parameters, through multiple and various exposure times of the zincation process and zincation solution concentration effect on the $\mathrm{Ni} / \mathrm{Au}$ surface roughness and aluminum dissolution rate on the bond pad during multiple zincation process. The ball shear strength was evaluated between eutectic $37 \mathrm{~Pb} / 63 \mathrm{Sn}$ solder ball and under bump metallurgy (UBM) interfaces across multiple zincation process. Scanning Electron Microscope (SEM), Energy Dispersive X-Ray (EDX), Atomic Force Microscopy (AFM), Focused Ion Beam (FIB) and ball shear tester were used as analytical tools. The results suggest that the multiple zincation process consistently produces a smoother surface of ENIG UBM and consequently provides a better shear strength.
\end{abstract}

Key words: Zincation, electroless nickel immersion gold (ENIG), under bump metallurgy (UBM)

\section{INTRODUCTION}

Electroless nickel Immersion Gold (ENIG) as under bump metallurgy (UBM) of the bond pads on a silicon wafer is gaining interest in flip chip packaging because of its relatively low cost and simple process. Electroless refers to the autocalytic or chemical reduction of metal ions plated onto a base substrate from an aqueous solution ${ }^{[1]}$. The depositions are very uniform because no external current is required hence the deposition rate is not influenced by current distribution in the plating cell. The deposition is very selective, only occurring on the exposed metallization bond pad.

Aluminum is the dominant material for IC bond pad metallization since its introduction to semiconductor world. Pure aluminum and high aluminum alloys quickly form a tenacious, refractory ceramic oxide on the surface that requires special treatment to remove before achieving successful soldering. This step applied to most of the methods in making interconnections from the bond pad on the Integrated Circuit (IC) die to the leadframe. In electroless nickel immersion gold (ENIG) UBM process, the surface treatments starts with surface cleaning to remove any contaminant that are presents on the bond pad surface, followed by an activation process to activate the bond pads for better nucleation for the subsequent process through the micro-etching of aluminum oxide. Following is a pre-plating process called zincation. During the zincation process, aluminum oxide is completely removed and is replaced with a thin layer of zinc metal. The zinc protects the aluminum from re-oxidation until it is ready to be plated. Once this process is performed, the aluminum

Corresponding Author: $\quad$ M.K. $\quad$ Md Arshad, School of Microelectronic Engineering, Kolej Universiti Kejuruteraan Utara Malaysia (KUKUM), Blok A, Kompleks Pusat Pengajian KUKUM, Jalan Kangar-Arau, 02600 Jejawi, Perlis, Malaysia, Tel: 604-9798435, Fax: 604-9798305 
coated zinc can then be electrolessly plated with nickel followed by immersion gold.

Zincation relies on the electrochemical exchange reaction between zinc ions in the solution and aluminum metals to deposit zinc metal at the expense of aluminum dissolution (etching) ${ }^{[2]}$. Zincation is one of the most suitable processes to activate the aluminum surface for the electroless technique ${ }^{[3]}$. Multiple immersion zincation with minimum aluminum attack/etching is necessary for achieving better adhesion strength of the zinc layer ${ }^{[4,5]}$. However, common practice is a double zincation process ${ }^{[3-9]}$. It is essential to etch the deposited zinc with a suitable acid solution between the consecutive zincation steps in order to successfully carry out the multiple zincation operation. Previous studies have shown that the zincation process has significant impact on the resultant zinc layer morphology, which in-turn directly correlates with the ENIG bump quality and its shear strength to the solder ball interface ${ }^{[2]}$. Therefore in this study, the focus is into the factors of a third zincation process, zincation exposure time and zincation solution concentration which may give significant impact on the UBM.

A series of systematic experiments are carried out to have better understanding of these factors to the surface morphology, surface roughness and dissolution rate to the aluminum bond pad. The correlations between these surfaces appearance to the solder ball shear strength is also studied. The information presented may provide the best condition for surface treatment processes to produce a better surface appearance and lead to a more reliable under bump metallurgy (UBM) using electroless nickel immersion gold (ENIG) technique.

\section{MATERIALS AND METHODS}

The 6" Si wafer with Al bond pads composition of $1 \% \mathrm{wtSi}$ and $0.5 \% \mathrm{wtCu}$ were used in this experiment. The bond pads were 2 um thick with an opening of 320 $\mu \mathrm{m}$ while the rest of the metals were passivated with a $0.9 \mu \mathrm{m}$ thickness silicon nitride.

The chemicals used were a newly prepared and experiments were carried out in laboratory scale using small beakers and heating plates that were equipped with fuzzy electronic contact thermocouples. The system was used to heat, control the temperature and agitate the plating solution. For $\mathrm{pH}$ measurement, a microcontroller $\mathrm{pH}$ digital meter was used. Two point calibrations were performed using standard $\mathrm{pH}$ solution before start of use for optimum accuracy.
Prior to the deposition of electroless nickel immersion gold (ENIG), the wafer backside was covered with a high temperature as insulating layer to prevent deposition of nickel at the back of the wafer and also to prolong the life cycle of the chemical solution. Then, the wafer was cleaned in a weak alkaline solution at $70^{\circ} \mathrm{C}$ containing aqueous solution of phosphate for 7 minutes. After that, the cleaned aluminum pads were activated via the wet-etching for 60 s to remove the aluminum oxide on the surface at room temperature with phosphoric acids solution. Following next is the first zincation process whereby a zinc coating was applied using an immersion zinc to prevent re-oxidation of the cleaned surface on the bond pad. Double and followed by triple zincation was used in this experiment to get a fine, smooth and homogeneous zinc cluster on the surface. However, an acid etch using nitric acid solution was performed for 10 s between consecutive zincations to remove zinc, at room temperature. The wafer must be rinsed with DIwater between process steps to avoid chemical mixture to the subsequent process.

Various zincation exposure times (30s and 60s), multiple zincations (first, second and third zincation) and different zincation solution concentrations (20\% up $100 \%$ with interval of $20 \%$ ) were used as variable parameters for the experiments. Once the aluminum surfaces have been coated with zinc, the sample preparation then proceeds to electroless nickel (EN) deposition for 25 minutes at $85^{\circ} \mathrm{C}$ to obtain about 7 $10 \mu \mathrm{m}$ thick layer of nickel. The nickel plated surfaces were then immersed into a gold plating solution for 5 $\min$ at $85^{\circ} \mathrm{C}$ to obtain a thin layer of gold $(0.05-0.07$ $\mu \mathrm{m}$ thickness) on the surface. The general process flow and associated parameter are tabulated in Table 1.

Scanning Electron Microscopy (SEM) and Atomic Force Microscopy (AFM) were used for surface morphology and roughness. Elemental Dispersive Xray (EDX) provided elemental analysis data. Focused Ion Beam (FIB) was used for precise cross-sectioning at the aluminum bond pad after each zincation process and followed by aluminum thickness measurement from the display image on the computer screen. The thickness after each zincation process is then compared with the initial bond pad thickness.

The eutectic solder balls of $37 \mathrm{~Pb} / 63 \mathrm{Sn}$ composition with a diameter of $300 \mu \mathrm{m}$ were manually attached onto the UBM. Flux was used to hold to the solder ball onto UBM as the entire assembly moves into the reflow 
Table 1: Process flow and parameter

\begin{tabular}{llll}
\hline & & Parameter & Remark \\
\hline 1 & Coat wafer backside & $\mathrm{RT}$ \\
2 & Cleaning & $350 \mathrm{~s}, 70{ }^{\circ} \mathrm{C}, \mathrm{pH} 10$ & \\
3 & Activation & $60 \mathrm{~s}, \mathrm{RT}, \mathrm{pH}<1$ & \\
4 & $1^{\text {st }}$ Zincation & $60 \mathrm{~s} / 30 \mathrm{~s}, \mathrm{RT}, \mathrm{pH} 12$ & Some samples were directly subjected to electroless nickel immersion gold after $1^{\text {st }}$ zincation \\
5 & $1^{\text {st }}$ Zinc Removal & $10 \mathrm{~s}, \mathrm{RT}, \mathrm{pH}<1$ & \\
6 & $2^{\text {nd }}$ Zincation & $60 \mathrm{~s} / 30 \mathrm{~s}, \mathrm{RT}, \mathrm{pH} 12$ & Some samples were directly subjected to electroless nickel immersion gold after $2^{\text {nd }}$ zincation \\
7 & $2^{\text {nd }}$ Zinc Removal & $10 \mathrm{~s}, \mathrm{RT}, \mathrm{pH}<1$ & \\
8 & $3^{\text {rd }}$ zincation & $60 \mathrm{~s} / 30 \mathrm{~s}, \mathrm{RT}, \mathrm{pH} 12$ & Some samples were directly subjected to electroless nickel immersion gold after $2^{\text {nd }}$ zincation \\
9 & Electroless Ni & $25 \mathrm{~min}, 85^{\circ} \mathrm{C}, \mathrm{pH} 4.8$ & \\
10 & Immersion Au & $5 \mathrm{~min}, 85^{\circ} \mathrm{C}, \mathrm{pH} 4.8$ & \\
\hline RT : Room Temperature &
\end{tabular}

oven. It also helps to facilitate the solder wettability during reflow. Furthermore, ball shear strength was evaluated using ball shear tester to understand the correlation between surface roughness and morphology to solder ball and UBM integrity. The shear force was set at 500 gram and the back-off height to $30 \mu \mathrm{m}$. The ball shear test was evaluated for different zincation exposure time across multiple zincations.

\section{RESULT AND DISCUSSION}

Effect of surface cleaning and activation processes: The effect of each process stage of aluminum treatment was investigated via Atomic Force Microscopy (AFM) and Scanning Electron Microscope (SEM) for surface topography and morphology. After the cleaning process, the wafer was then subjected to the activation process. This activation process is needed to activate the aluminum surface for subsequent zincation process through the etching process. An acidic solution was used to micro-etch the oxide layer on aluminum surfaces. Figure 1 shows the surface topography and morphology after cleaning and activation process. There are no significant differences on the surface morphology and topography with these processes.

Effect of multiple and various exposure time of zincation process: Once the cleaning and activation process were completed, the zincation process was applied to the bond pad surface to completely remove the oxide layer and prevent the surface from reoxidizing again. This can be achieved through a reduction and oxidation process while depositing zinc. The process will oxidize the aluminum metal from the surface thus releasing electrons to reduce zinc ions from solution to form zinc metal as shown in the formulation below. Zinc coating is also needed to initiatethe

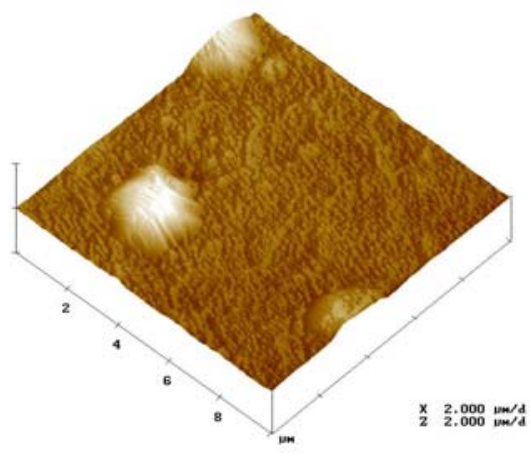

(a)

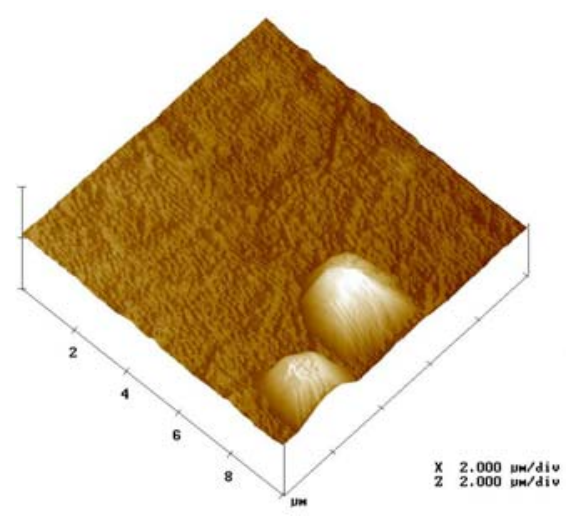

(b)

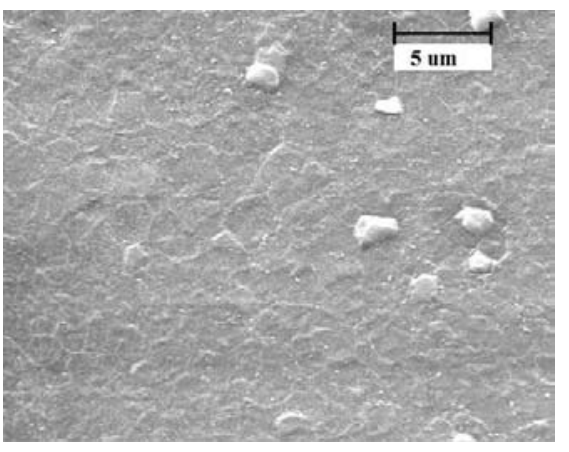




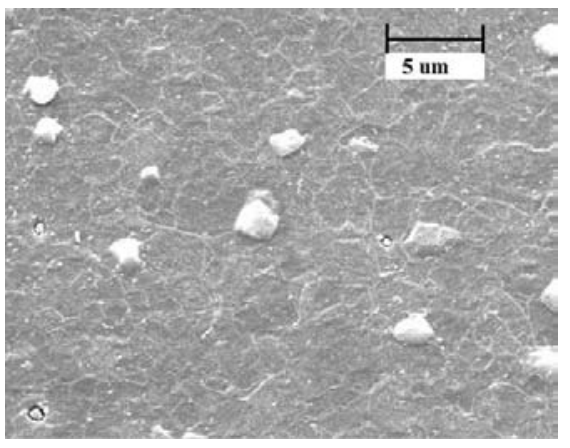

(d)

Fig. 1: $\quad$ Surface topography using AFM (a-b) and Surface Morphology using SEM (c-d): (a) Topography image after cleaning process (b) Topography image after activation process (c) Morphology image after cleaning process (d) Morphology image after activation process

reaction at subsequent process. Figure 2 to 4 show the appearances of the bond pad surface after each step of zincation process compared to the initial bond pad. The first zincation process produces a rough zinc layer and preserved the contour of the initial bond pad with nodules present on the surface. The second zincation process step appeared to be quite uniform in size with a continuous zinc layer. However, the contours of the second zincation also preserved the contour of the initial bond pads but with the nodules getting finer and smaller. The third zincation process becomes a continuous zinc layer. After this process, the zinc layer form together like an isolated island and the nodules are much smaller and at almost the same level as the zinc. Obviously, the third number of zincation process will improve the surface roughness due to dissolved aluminum in the solution while depositing the zinc layer. Figure 2 can be used to support the image in Fig. 3 and 4 to show evidence that the third zincation process produces better surface roughness.

In performing the multiple zincation process, it is necessary to etch the zinc deposited between the consecutive zincation steps prior to next zincation process. This process is known as zinc removal. The zinc removal or chemical etching process that was performed in between zincation processes (first and second, second and third) will refine the previously deposited zinc or preferentially dissolve the zinc seed into the zinc removal solution ${ }^{[4,9]}$. In this study we found that the zinc had been removed completely as shown in Table 2. If the zinc layer still present after the zinc removal process it will stop growing as the growth is interrupted by the etching step whereby the wafer is moved out from the zincation bath. Fresh zinc will form during the next zincation step resulting in a fine and

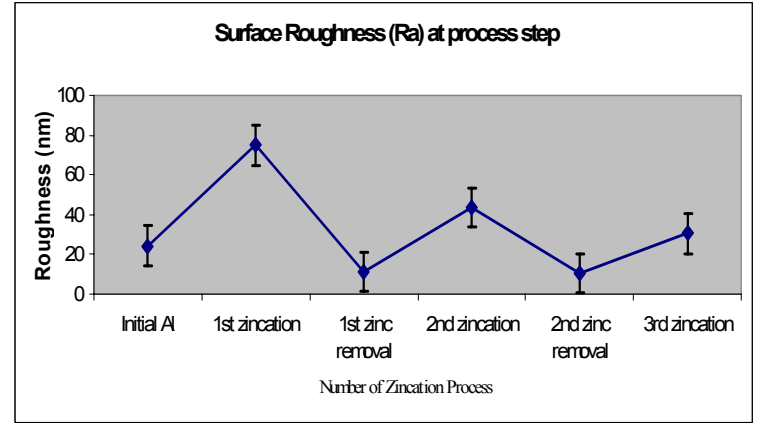

Fig. 2: Surface roughness of initial bond pad compared to zincation process

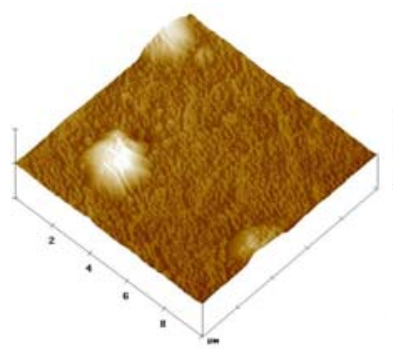

(a)

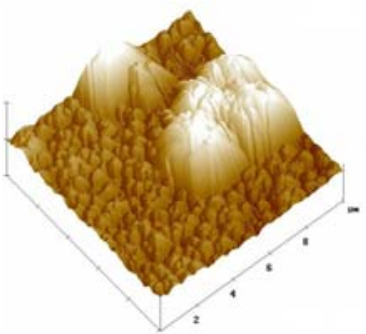

(b)

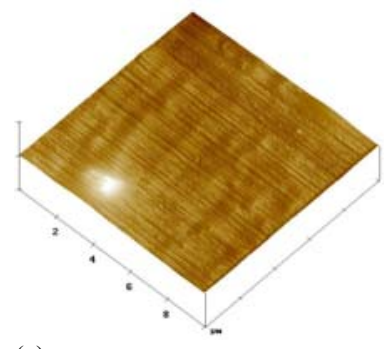

(c)

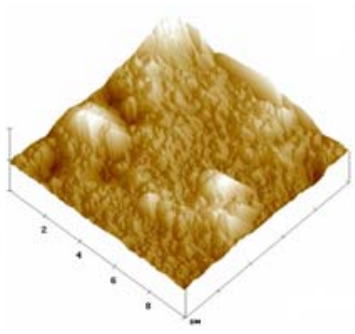

(d)

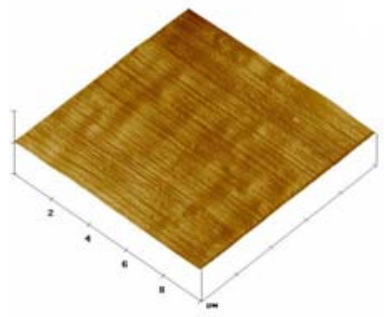

(e)

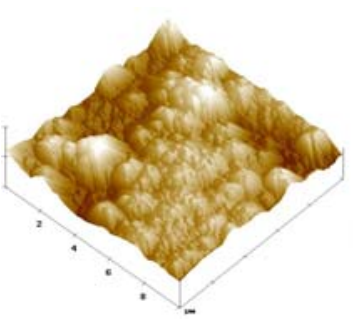

(f)

Fig. 3: $\quad$ Surface topography images using AFM of (a) Initial bond pad surface, (b) first zincation (c) first zinc removal (d) second zincation (e) second zinc removal (f)third zincation

uniform zinc after multiple zincation steps (second and third zincation).

The chemicals used in this experiment are slightly different from conventional zinc solutions. In conventional zinc solutions, first zincation is not uniform and only a small amount of zinc will be deposited. Only after the second zincation process, the zinc layer covers the entire surface and is considered 


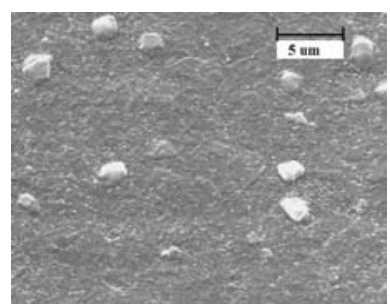

(a)
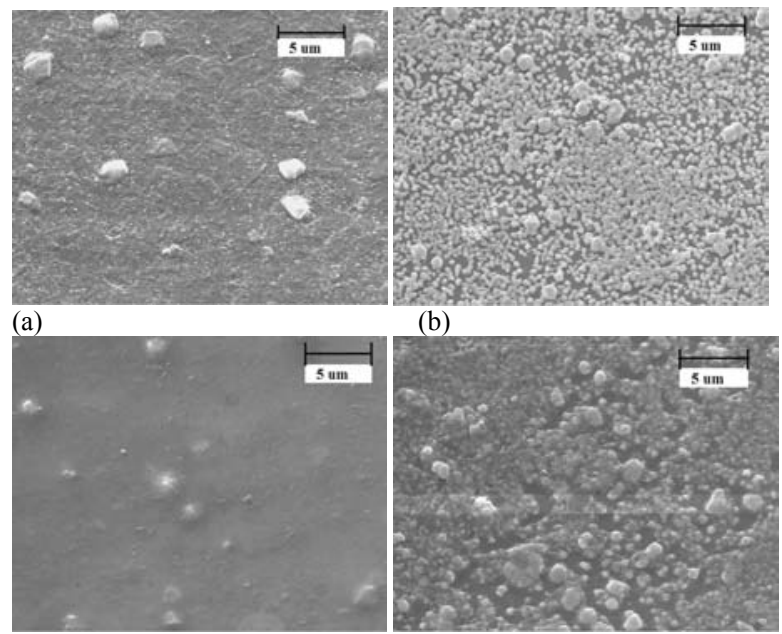

(c)

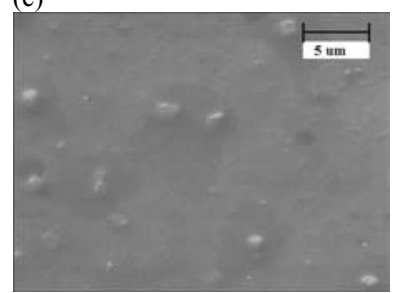

(e)

Fig.4: (b)

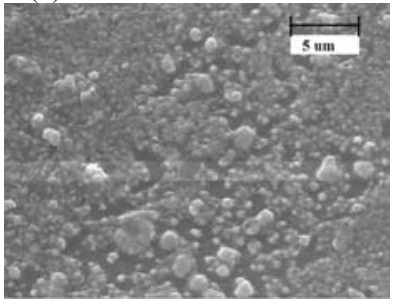

(d)

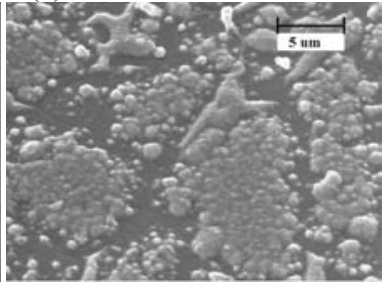

(f)

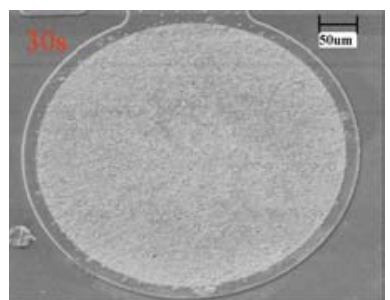

(a)

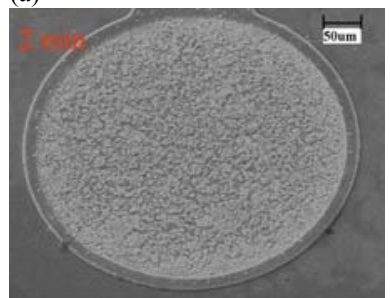

(c)

Fig. 5: Surface morphology of various exposure times of zincation process (a) 30 seconds (b) 60 seconds (c) 2 minutes (d) 5 minutes

Effect of Zincation Exposure Time across Multiple Zincation to Aluminum Thickness

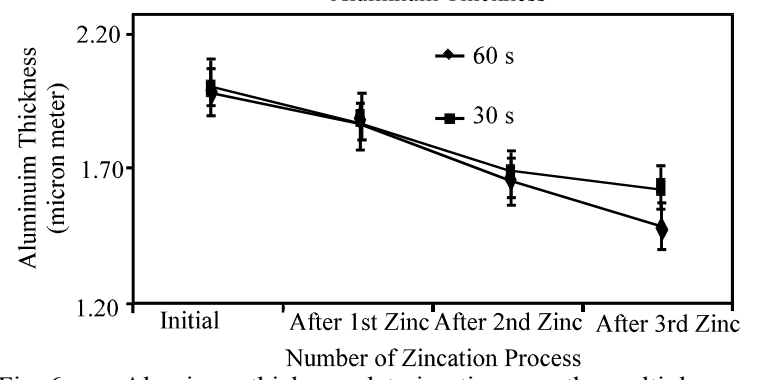

Fig. 6: Aluminum thickness deterioration over the multiple zincation process

Oxidation: $\mathrm{Al} \rightarrow \mathrm{Al}^{3+}+3 \mathrm{e}^{-} \mathrm{E}^{0}=-2.31 \mathrm{~V}$

Some samples of the first zincation process were then subjected to various dipping times during the zincation process. Figure 5 shows the various surface morphologies of the zinc layer that was deposited in this study. For $30 \mathrm{~s}$ of the single zincation treatment, the whole aluminum surface was covered by fine zinc. Between 30s and 60s, the zinc layer coverage shows no significant difference as shown in Fig. $5 \mathrm{a}$ and $\mathrm{b}$. However the size of zinc deposit are growth larger after 2 minutes and 5 minutes exposure times respectively but a good coverage on the bond pad surface is still maintained. The result shows the longer deposition time would cause zinc to keep growing unless the growth is interrupted or stopped by any reason i.e. moved out the sample from solution. Thus, it produces a thick and high density of zinc that roughens the surface appearance. This proves the result of study by Lin and Chang ${ }^{[3]}$. Since the surface morphology of samples with 30 s and 60s exposure time is almost identical, this was then used to proceed to electroless nickel process. 


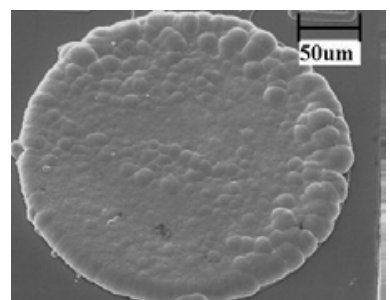

(a)
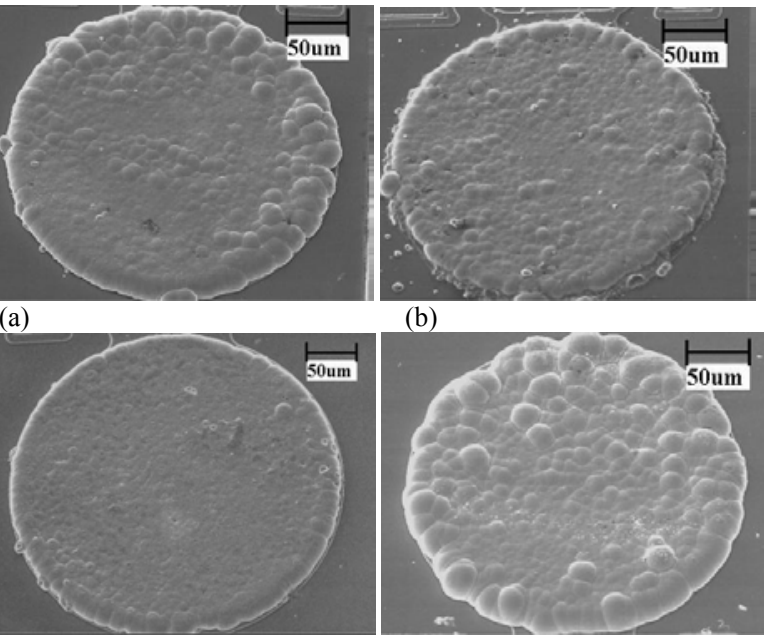

(c)

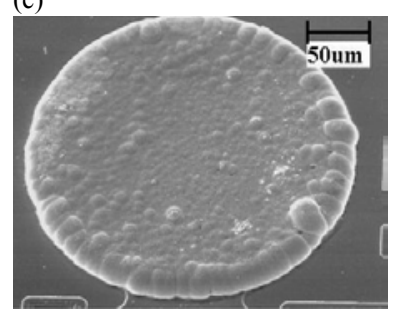

(e)

Fig. 7: (b)

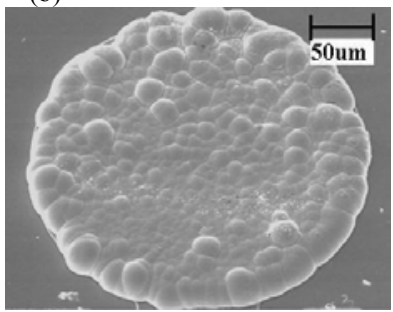

(d)

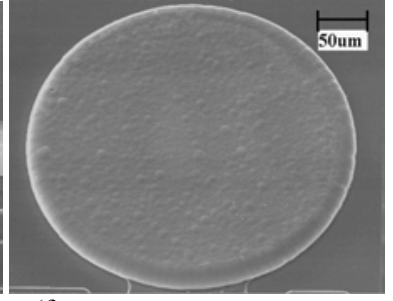

(f)
Surface morphology images using SEM of exposure time of (a) nickel surface of first zincation (30s zincation), (b) nickel surface of second zincation (30s zincation), (c) nickel surface of third zincation (30s zincation), (d) nickel surface of first zincation (60s zincation), (e) nickel surface of second zincation (60s zincation), (f) nickel surface of third zincation (60s zincation)

As mentioned previously, the zincation process involved reduction and oxidation processes. This phenomenon caused deterioration to aluminum thickness ${ }^{[8]}$, therefore it is necessary to find out the aluminum dissolution rate while depositing zinc. The samples were then subjected to FIB micromachining for precise cross sectioning on the bond pad followed by aluminum thickness measurement directly from the screen over the selected width with the aid of a cursor. Figure 6 shows the results of aluminum thickness with no significant difference between 30s and 60s exposure time. However, with a $30 \mathrm{~s}$ exposure time, slight differences of aluminum dissolution is found as compared to 60 s which may not reduce reliability.

Effect of zincation exposure time to nickel surface appearance: Furthermore the surface appearance of the electroless nickel deposition that was initiated from a differently zincated bond pad which translates as different surface roughness, as discussed previously was also studied. Morphology images were taken using

SEM at 350x magnification to complement the topography image from AFM for a bigger visualizes area. From the micrograph images in Fig. 7, nodules still visible even after nickel deposited with the first and second zincation treatment. Second zincation treatment produces a slightly better surface appearance but observation shows inconsistency from bond pad to bond pad. However, the third times of zincation process provides better consistency in producing a smooth and homogenous nickel surface.

This shows that, the roughness of the differently zincated surface as shown in Fig. 3 and 4, will unavoidably be transferred to the nickel surface appearance. Therefore, will be an advantage to have the initial bond pad surface free from nodules with a smooth bond pad surface being the most preferred. This simplified the surface treatment process with less number of zincation to produce a smooth and homogeneous nickel surface. The industrial standard practice is a double zincation process, however in this study a triple zincation is needed to produce consistent smooth surface from bond pad to bond pad due to the existence of nodules at initial bond pads surface.

Effect of zincation concentration solution to electroless nickel surface morphology: The intention of this study was to understand the influence of the zincation concentration solution to zinc surface and consecutively to the electroless nickel surface appearances. The experiment was carried out with a concentration between $20 \%$ up to $100 \%$. The $50 \%$ diluted (or $50 \%$ concentration) is recommended by the supplier for aluminum bond pad treatment. The result in Fig. 8 shows that the third zincation process produces consistently smooth nickel surface across all the concentration. Nickel surface appearances for a double zincation are quite smooth for the concentration from $60 \%$ to $80 \%$. However observation shows it inconsistencies between bonds pad to bond pad surfaces. This was suspected due to second zincation process not able to refine the variation of nodules size that was presence initially on the bond pad. Lastly, for first zincation, it produces large nodules on the surface across all the concentration.

This result also shows that there is no significant influence of zincation solution concentrations to the nickel surface appearance especially when it is subjected to the third zincation. Qi G-J et al. ${ }^{[10]}$ mentioned that a diluted solution leads to smooth and small-grained zinc layer. In comparison to the results obtained from the work reported here, this is true only if it refers to the first zincation process and it does not 
Am. J. Applied Sci., 4 (3): 133-141, 2007

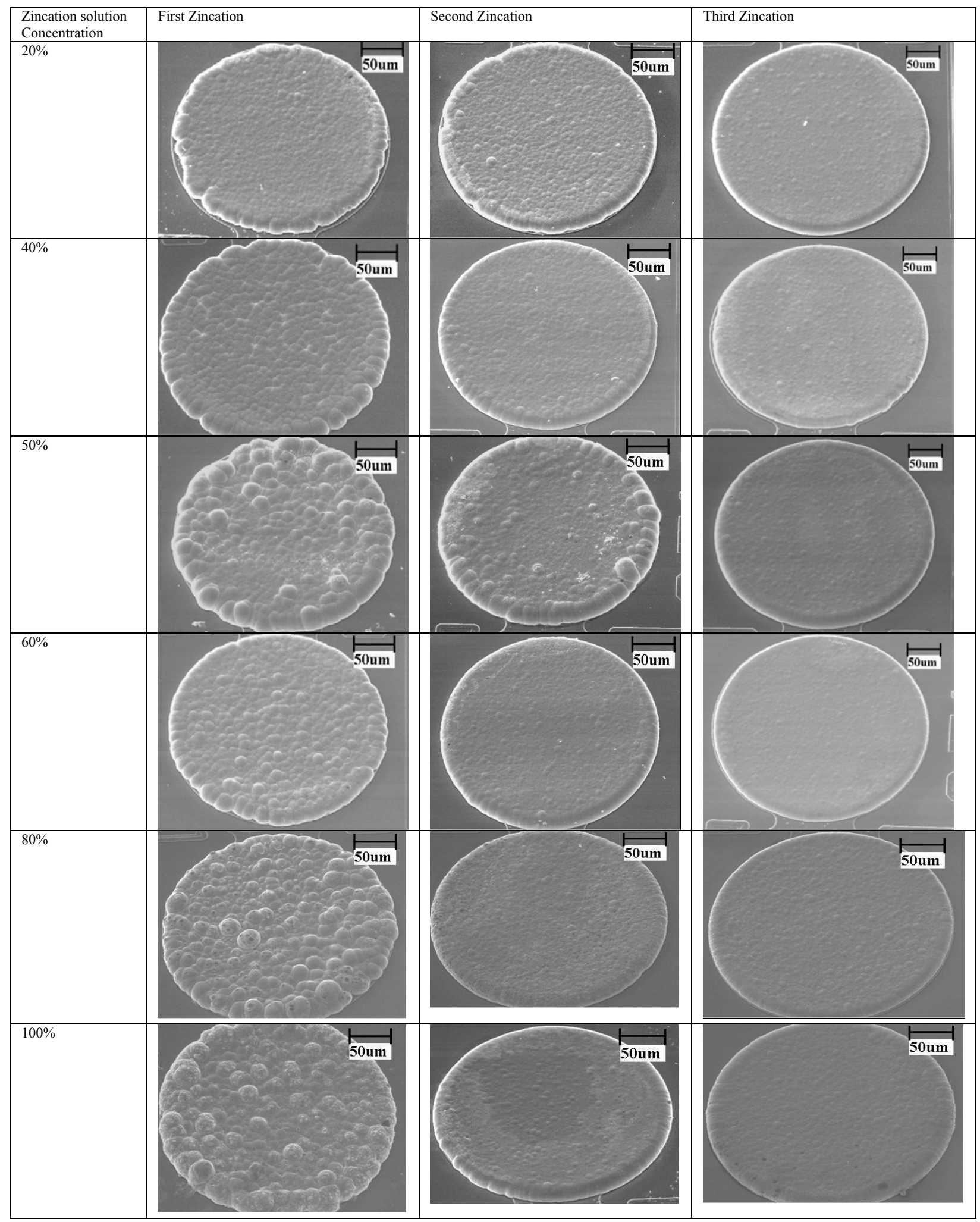

Fig. 8: Nickel surface appearances for several zincation concentration solution 


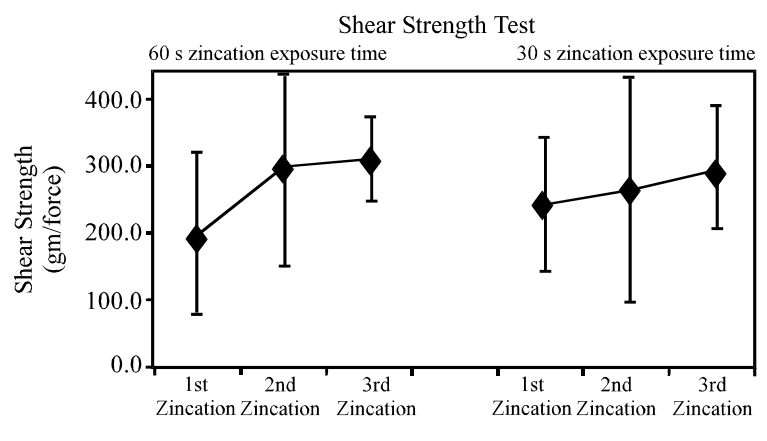

Number of Zincation and Exposure Time

Fig. 9: Shear strength of electroless nickel immersion gold as a function of different exposure time during the zincation process

reflect the results of second and third zincation process. The third zincation produces a better $\mathrm{Al}$ bond pad surface and this will be transferred to the nickel surface regardless of the zincation solution concentration.

Shear strength test: Ball shear test was conducted to determine the correlation between UBM surface roughness and morphology to the ball shear force. The third zincation produces a better shear strength regardless of the zincation exposure time (either $60 \mathrm{~s}$ or 30s) as shown in Fig. 9. The second zincation with a 60 s exposure time also produces almost a good result as the third zincation process. If the three sigma error bars is not considered then the second zincation with $60 \mathrm{~s}$ exposure is identical to the third zincation result. This might be the reason the second zincation is considered optimum for zincation process that has been practiced by the industry ${ }^{[3-9]}$ especially with 60 s zincation time.

This result also proved to be in support of previous study, whereby the rough and coarse surface adversely affects the ball shear force ${ }^{[6]}$. This detrimental effect was suspected to be due to the formation of high stress points in the rough and coarse grain size of UBM surfaces. The shear strength test result also indirectly supported the previous observation that has been made for the third zincation process which consistently produces a better surface roughness and surface morphology with smaller error bars (based on 3sigma) regardless of exposure time. Observation shows that the majority of the failures occurred within the bulk solder ball. However, for bump with high shear force the failures occurred at the $\mathrm{Al}$ layer. The failures also occurred at the UBM and solder interfaces which are believed to be in between the Ni-solder intermetallic layer. No failures were observed at the Al and UBM interfaces.

\section{CONCLUSION}

Longer zincation time produces a thick and highdensity zinc layer that caused rough surface appearances. A third zincation process consistently produces a smooth and continuous zinc film on the surface across the bond pads, exposure time and zincation concentration solution and is consecutively transferred to the nickel surface appearance. In this study, number of zincation process plays an important role to further reduce the nodule that presence initially on the bond pad. The third zincation process, which translates into smooth surface on nickel, provides better adhesion between UBM and solders ball interfaces.

\section{ACKNOWLEDGEMENTS}

The author wishes to thank Ministry of Science, Technology and Innovation (MOSTI), Malaysia, under the IRPA grant no. 09-02-02-0107-EA259 for financial support. The authors also would like to extend the acknowledgements to Failure Analysis Lab at MIMOS Berhad, Failure Analysis Lab at ON Semiconductor and Colloidal Lab at University of Malaya, Malaysia for supporting the analytical tools.

\section{REFERENCES}

1. Simon, J., E. Zakel and H. Reichl, 1990. Electroless deposition of bumps for TAB technology. Electronic Components and Technology Conf. Proceeding 40th, 20-24 May, pp: 412-417.

2. Qi, G., X. Chen and Z. Shao, 2002. Influence of bath chemistry on zincate morphology on aluminum bond pad. Thin Solid Films, 406: 204209.

3. Lin, K-L. and S-Y. Chang, 1996. The morphologies and the chemical states of the multiple zincating deposits on the $\mathrm{Al}$ pads of $\mathrm{Si}$ chips. Thin Solid Films, 288: 36-40.

4. Ng. W-C., T-M. Ko, W. Chen and G-J. Qi, 1998. The effect of immersion zincation to the electroless nickel under-bump materials in microelectronics packaging. Electronics Packaging Technology Conference, Proceedings of 2nd, 8-10 Dec., pp: 8994.

5. Ostmann, A., J. Simon and H. Reichl, 1993. The pretreatment of aluminum bond pads for electroless nickel bumping. Multi-chip Module Conference, Proceeding IEEE, 15-18 Mar., pp: 74-78. 
6. Yau, E-W-C., J-F. Gong and P. Chan, 2003. Al pad surface morphology effect on flip-chip solder bump shear strength. Microelectronics Reliability, 44: 323-331.

7. Hutt, D.A., C-Q. Liu, P.P. Conway, D.C. Whalley and S.H. Mannan, 2002. Electroless nickel bumping of aluminum bond pads-Part I: Surface pretreatment and activation. Electronic Components and Packaging Technologies, 25: 8797.

8. Strandford, A.J.G., S. Popelar and C. Jauerning, 2002. Interconnecting to aluminum and copperbased semiconductor (electroless-nickel/gold for solder bumping and wire bonding). Microelectronic Reliability, 42: 265-283.
9. Lee, S-K., J-G. Jin, Y-H. Kim and J-H. Lee, 2001. A study on the nucleation behavior of zinc particles on aluminum substrate. Intl. Symp. on Electronics Material and Packaging, 19-22 Nov., pp: 73-78.

10. Qi, G-J., L.G.J. Fokkink and K-H. Chew, 2002. Zincating morphology of aluminum bond pad: It influence on quality of electroless nickel bumping. Thin Solid Films, 406: 219-223. 